\title{
Intralymphatic immunotherapy for allergic rhinoconjunctivitis: a systematic review and meta-analysis*
}

\author{
Minh P. Hoang ${ }^{1,2,3}$, Kachorn Seresirikachorn ${ }^{1,2}$, Wirach Chitsuthipakorn ${ }^{4,5}$, \\ Kornkiat Snidvongs ${ }^{1,2}$
}

' Department of Otolaryngology, Faculty of Medicine, Chulalongkorn University, Bangkok, Thailand

2 Endoscopic Nasal and Sinus Surgery Excellent Center, King Chulalongkorn Memorial Hospital, Bangkok, Thailand

${ }^{3}$ Department of Otolaryngology, Hue University of Medicine and Pharmacy, Hue University, Vietnam

${ }^{4}$ Center of excellence in Otolaryngology Head \& Neck Surgery, Rajavithi Hospital, Bangkok, Thailand

Department of Otolaryngology, College of Medicine, Rangsit University, Bangkok, Thailand

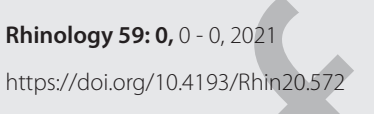

*Received for publication:

November 9, 2020

Accepted: December 15, 2020

\begin{abstract}
Background: Intralymphatic immunotherapy (ILIT) is a new route of allergen-specific immunotherapy. Data confirming its effect is restricted to a small number of studies.

Methodology: A systematic review with meta-analysis was conducted. The short-term ( $<24$ weeks), medium-term (24-52 weeks), and long-term ( $>52$ weeks) effects of ILIT in patients with allergic rhinoconjunctivitis (ARC) were assessed. The outcomes were combined symptom and medication scores (CSMS), symptoms visual analog scale (VAS), disease-specific quality of life (QOL), specific lgG4 level, specific lgE level, and adverse events.
\end{abstract}

Results: Eleven randomized controlled trials and 2 cohorts (483 participants) were included. Compared with placebo, short term benefits of ILIT for seasonal ARC improved CSMS, improved VAS and increased specific lgG4 level but did not change QOL or specific lgE level. Medium-term effect improved VAS. Data on the long-term benefit of ILIT remain unavailable and require longer term follow-up studies. There were no clinical benefits of ILIT for perennial ARC. ILIT was safe and well-tolerated.

Conclusion: ILIT showed short-term benefits for seasonal ARC. The sustained effects of ILIT were inconclusive. It was well tolerated.

Key words: allergy, IgE, intralymphatic immunotherapy, pollinosis, allergic rhinitis

\section{Introduction}

The Allergic Rhinitis and Its Impact on Asthma (ARIA) guidelines and the International Consensus Statement on Allergy and Rhinology suggest allergen-specific immunotherapy (AIT) for patients with moderate to severe allergic rhinoconjunctivitis (ARC) who were not improved by medications ${ }^{(1,2)}$. Subcutaneous immunotherapy (SCIT) and sublingual immunotherapy (SLIT) are the standard treatments of $\mathrm{AIT}^{(3,4)}$. However, these conventional treatments require a long treatment duration, for example, SCIT requires 50-80 injections over 3 years ${ }^{(5)}$. Intralymphatic immunotherapy (ILIT) is a form of AIT that can modify the IgE mediated hypersensitivity of $\mathrm{ARC}^{(3)}$. ILIT aims to improve the efficacy of AIT by administering specific allergens directly into the lymphoid organs $s^{(5)}$, based on the "geographic concept of immunogenicity" that the immune responses can be initiated only in secondary lymphatic organs such as lymph nodes ${ }^{(6,7)}$. Inguinal and cervical lymph nodes are chosen as the injection sites of ILIT because they are superficially accessible ${ }^{(5)}$. Inguinal lymph nodes are 1 to $1.5 \mathrm{~cm}$ in size which can be detected by ultrasound as hypoechoic nodules. Specific allergens are injected into these lymph nodes by using a 28 -gauge needle under ultrasound guidance. Current ILIT protocols suggest three injections into the lymph nodes over a period of eight weeks ${ }^{(8,9)}$. These protocols require fewer injections and a shorter treatment duration than conventional AIT. Thus, ILIT becomes an alternative treatment option for patients with ARC who did not adhere to the conventional $\mathrm{AIT}^{(10)}$.

The efficacy of ILIT on allergen tolerance and mitigation of the 
ARC severity has been demonstrated ${ }^{(8)}$, resulting in the increasing ILIT acceptance ${ }^{(11)}$. While the long-term benefits of SCIT and SLIT have been reported ${ }^{(12)}$, there is insufficient data regarding the long-term effects of ILIT. There is also a lack of systematic reviews and meta-analyses assessing the effectiveness and adverse events of ILIT. This systematic review aims to evaluate the efficacy and safety of ILIT in treating patients with ARC.

\section{Materials and methods}

The study protocol was submitted to the PROSPERO (reference number CRD42020188260). This systematic review was conducted in accordance with The Preferred Reporting Items for Systematic Reviews and Meta-Analyses (PRISMA) ${ }^{(13)}$. Electronic searches with MEDLINE, SCOPUS, and EMBASE were conducted. Manual searches for the references of the included studies and the additional sources were conducted. The date of the last search was 21 July 2020. Combinations of the MESH terms and text words were "rhinitis, allergic", "allergic rhinitis", "nasal allergy", "hay fever", "rhinoconjunctivitis", "lymph nodes", "lymph*", "intralymph*", "intralymphatic immunotherapy", and "injection, intralymphatic".

\section{Eligibility criteria}

Clinical trials of ILIT in patients with ARC were included. Patients with ARC at any age were eligible. The diagnostic criteria of ARC followed the ARIA guidelines. The ARC diagnosis was confirmed by either skin prick test (SPT) or serum-specific $\lg \mathrm{E}^{(14)}$. Studies with mixed populations of ARC and nonallergic rhinitis were included if data of the patients with ARC were reported separately. Protocols of ILIT with any type of specific allergen, dosage, treatment duration and follow-up period were accepted. Randomized controlled trials (RCTs) which assessed the effects of ILIT compared with either placebo or standard AIT (SCIT or SLIT) were eligible for the assessment of ILIT effectiveness. All clinical studies with any study design (e.g. case series, cohort, clinical controlled trial, etc.) were eligible for the assessment of ILIT safety. Conference abstracts and studies published in languages other than English were excluded.

\section{Study selection process and data extraction}

Two authors (MPH and WC) independently screened the titles and abstracts of the studies based on predetermined eligibility criteria. Full texts of the screened studies were obtained for the final study selection. Two authors (MPH and KSe) separately performed data extraction. If there was incomplete data during the data collection, the corresponding author of that study was contacted for additional data. Disagreements over the selection and extraction processes were resolved by thoroughly discussing among the authors or by consulting the fourth author (KSn). The extracted data included: sample size, age, gender, allergen extract, dosage, interval between the injections, booster dose, and follow-up period. The effects of ILIT were assessed after finishing three injections at $<24$ weeks for short-term effects, 24-52 weeks for medium-term effects, and $>52$ weeks for long-term effects.

\section{Outcome measures}

Primary outcomes were the combined symptom and medication score (CSMS), symptom score (SS), medication score (MS), visual analog scale (VAS) of ARC symptoms, and disease-specific quality of life (QOL). These outcomes are recommended by the European Academy of Allergy and Clinical Immunology (EAACI) and the Food and Drug Administration (FDA) as primary outcomes for AIT trials ${ }^{(15)}$. The CSMS is equally weighted between the SS and MS, and reflects both the symptom severity and the intake of rescue medication ${ }^{(15)}$. Secondary outcomes were specific lgG4 level, specific IgE level, and adverse events. Adverse events were categorized as local reaction, systemic reaction, anaphylaxis, and death.

\section{Quality of the included studies}

Two authors (MPH and WC) independently evaluated the quality of the included studies. Risks of bias were assessed according to the Cochrane Collaboration's tool(16) to determine the quality of each RCT. Five domains were evaluated which included random sequence generation, allocation concealment, blinding of outcome assessment, incomplete outcome data, and selective outcome reporting. Each domain was determined as "low risk" of bias when the methods of the domain were sufficiently described, "high risk" when the respective domain has not been mentioned, or "unknown risk" when the domain was mentioned but insufficiently described. The quality of non-randomized studies was assessed by the methodological index for non-randomized studies (MINORS) with 8 domains for non-comparative studies or 12 domains for comparative studies ${ }^{(17)}$. Each domain had a score ranging from 0 to 2 . The total MINORS score of non-comparative studies was $0-16$ or $0-24$ for comparative studies. A total score of non-comparative studies below 11 and comparative studies below 16 represented high risk of bias.

Data synthesis and statistical analysis Meta-analysis was performed by using Review Manager (RevMan) version 5.4 ${ }^{(18)}$. Dichotomous data were analyzed and reported as risk ratio (RR) and $95 \%$ confidence interval $(\mathrm{Cl})$. Continuous data were presented as mean difference (MD) or standardized mean difference (SMD), standard deviation (SD), and $95 \% \mathrm{Cl}$. The standard error, median, range, and $95 \% \mathrm{Cl}$ were interpreted if the SD was not provided or could not be calculated. Discrepancies in the treatment effects among the trials were evaluated using heterogeneity (I2) statistics. An 12 of $<40 \%$, $40-60 \%$ and $>60 \%$ represented "low", "moderate" and "substantial" heterogeneity, respectively. When heterogeneity was low, a fixed-effect model was used. A random-effects model was used 


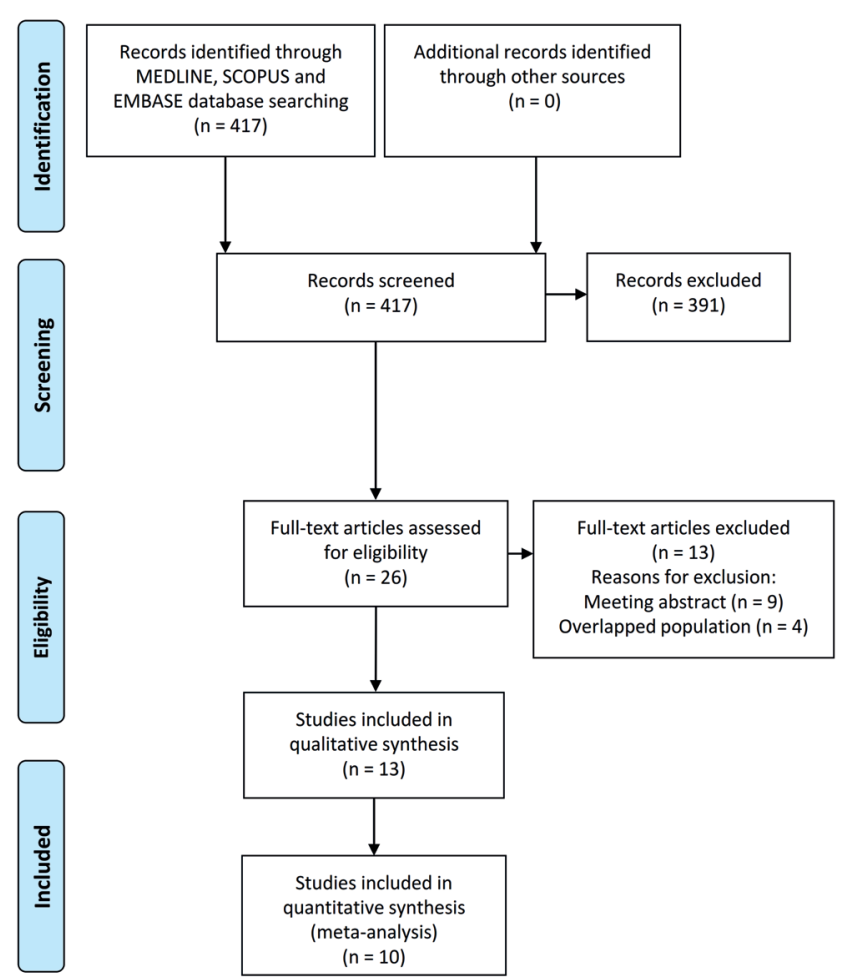

Figure 1. Flow diagram of study selection for the systematic review and meta-analysis.

if the heterogeneity was high for a more conservative estimate of the differences.

\section{Subgroup analyses}

Subgroup analyses by ARC subtype, age of the participant, and injection interval were conducted to assess the treatment effects and to explore the heterogeneity.

\section{Results}

\section{Study selection}

The electronic and manual searches retrieved 417 studies. Title and abstract screening removed 391 studies. Full-text screening for eligibility excluded 13 studies. Thirteen studies (11 RCTs and 2 cohorts) were included in the qualitative synthesis ${ }^{(8,9,19-29)}$ of which $10 \mathrm{RCTs}$ were included in the quantitative synthe$\operatorname{sis}^{(8,19-22,24-28)}$. A flowchart of the study selection is illustrated in Figure 1.

\section{Participants}

There were 483 participants ( $54.9 \%$ male). The mean age was 33.2 years. There were no patients younger than 15 years old. Ten RCTs assessed seasonal ARC patients. One $R C T^{(19)}$ and two cohorts assessed perennial ARC patients ${ }^{(9,23)}$. Three studies assessed only patients with moderate to severe $\operatorname{ARC}^{(21,24,27)}$. Characteristics of the included studies are shown in Table 1.

\section{Intervention}

Inguinal lymph nodes were the site of allergen administration in 12 studies $^{(8,19-29)}$. One study used cervical lymph nodes ${ }^{(9)}$. Pollen extracts were administered in 10 studies that assessed seasonal ARC patients ${ }^{(8,20-22,24-29)}$. In the 3 studies of patients with perennial ARC, mixed allergen extracts (house dust mites, dog, and cat dander) ${ }^{(23)}$, house dust mite allergen extracts ${ }^{(9)}$, and a recombinant MAT-Feld 1 from cat dander ${ }^{(19)}$ were used in each study. Non-standardized allergen extracts were used in 2 studies $^{(23,28)}$. The interval between the ILIT injections was 4 weeks in 12 studies ${ }^{(8,9,19,21-29)}$, and 2 weeks in 1 study $^{(20)}$. Escalating doses were administered in 2 studies $^{(19,22)}$ and fluctuating doses in 1 study (due to adverse events) ${ }^{(23)}$. The other 10 studies administered the

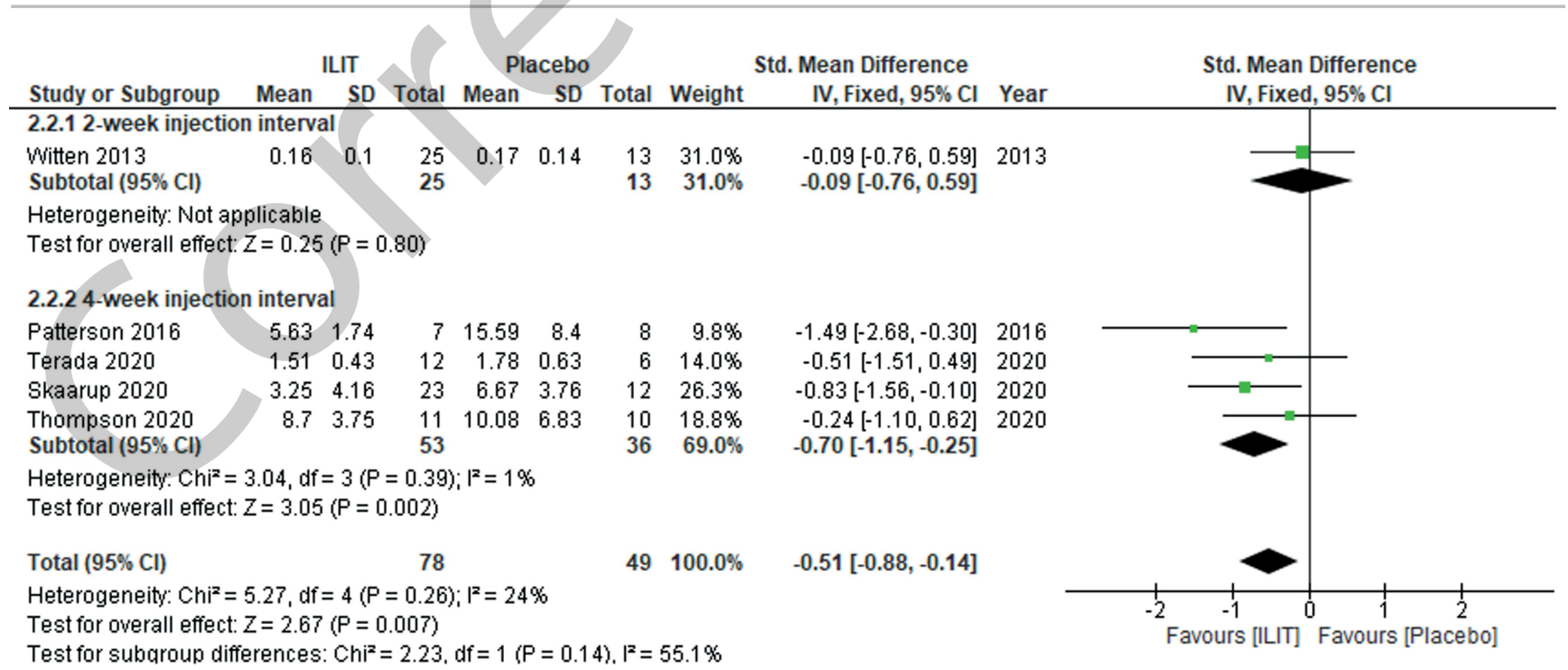

Figure 2. Short-term improvement in combined symptom and medication score and subgroup analysis by injection interval: intralymphatic immunotherapy versus placebo. ILIT = intralymphatic immunotherapy; $\mathrm{Cl}=$ confidence interval; $\mathrm{df}=$ degrees of freedom; Std. mean difference $=$ standardized mean difference. 
Table 1. Characteristics of the included studies.

\begin{tabular}{|c|c|c|c|c|c|c|c|c|c|c|c|}
\hline $\begin{array}{l}\text { First author, } \\
\text { Year }\end{array}$ & $\begin{array}{l}\text { Pa- } \\
\text { tients } \\
\text { (n) }\end{array}$ & Allergy & $\begin{array}{c}\text { Mean } \\
\text { age } \\
\text { (year) }\end{array}$ & $\begin{array}{l}\text { Male } \\
(\%)\end{array}$ & $\begin{array}{l}\text { ILIT } \\
\text { Allergen } \\
\text { extracts }\end{array}$ & $\begin{array}{l}\text { ILIT dose } \\
\text { per } \\
\text { injection }\end{array}$ & $\begin{array}{l}\text { Booster } \\
\text { Dose }\end{array}$ & Control & $\begin{array}{l}\text { Interval } \\
\text { (weeks) }\end{array}$ & $\begin{array}{l}\text { Fol- } \\
\text { low up } \\
\text { (weeks) }\end{array}$ & $\begin{array}{l}\text { Anaphy- } \\
\text { laxis } \\
\text { events }\end{array}$ \\
\hline $\begin{array}{l}\text { Senti }{ }^{(8)} \\
2008\end{array}$ & 112 & $\begin{array}{l}\text { Grass } \\
\text { pollen }\end{array}$ & 34 & 65.1 & $\begin{array}{l}\text { AHA grass } \\
\text { pollen extract }\end{array}$ & $1000 \mathrm{SQU}$ & No & $\begin{array}{l}\text { SCIT: same ex- } \\
\text { tract with ILIT }\end{array}$ & 4 & 144 & NR \\
\hline Senti(19), 2012 & 20 & $\begin{array}{l}\text { Cat dan- } \\
\text { der }\end{array}$ & 30.8 & 30 & $\begin{array}{l}\text { AHA MAT- } \\
\text { Feld1 }\end{array}$ & $\begin{array}{l}1 \mu \mathrm{g} \\
3 \mu \mathrm{g} \\
10 \mu \mathrm{g}\end{array}$ & No & $\begin{array}{l}\text { Placebo: AHA } \\
\text { and saline }\end{array}$ & $\begin{array}{c}4 \pm \\
3 \text { days }\end{array}$ & 55 & NR \\
\hline $\begin{array}{l}\text { Witten }{ }^{(20)} \text {, } \\
2013\end{array}$ & 43 & $\begin{array}{l}\text { Grass } \\
\text { pollen }\end{array}$ & 35.4 & 58.1 & $\begin{array}{l}\text { Alutard, Phle- } \\
\text { um pratense, } \\
\text { ALK-Abelló }\end{array}$ & $1000 \mathrm{SQU}$ & No & Placebo: saline & 2 & 14 & NR \\
\hline $\begin{array}{l}\text { Hylander }{ }^{(21)} \text {, } \\
2016\end{array}$ & 36 & $\begin{array}{l}\text { Birch / } \\
\text { Grass } \\
\text { pollen }\end{array}$ & 33.3 & 61.1 & $\begin{array}{l}\text { AHA birch or } \\
\text { grass pollen } \\
\text { extract }\end{array}$ & $1000 \mathrm{SQU}$ & No & $\begin{array}{l}\text { Placebo: Alutard, } \\
\text { ALK Abéllo }\end{array}$ & 4 & 36 & NR \\
\hline $\begin{array}{l}\text { Patterson }{ }^{(22)}, \\
2016\end{array}$ & 15 & $\begin{array}{l}\text { Grass } \\
\text { pollen }\end{array}$ & NR & NR & $\begin{array}{l}\text { AHA grass } \\
\text { pollen ex- } \\
\text { tract Center- } \\
\text { Al Phleum } \\
\text { pratense }\end{array}$ & $\begin{array}{l}50 \text { PNU } \\
100 \text { PNU } \\
250 \text { PNU }\end{array}$ & No & $\begin{array}{l}\text { Placebo: saline } \\
\text { with phenol }\end{array}$ & 4 & 10 & NR \\
\hline $\begin{array}{l}\text { Lee }^{(23)}, \\
2017\end{array}$ & 11 & $\begin{array}{l}\text { HDM, cat, } \\
\text { and dog }\end{array}$ & 41.6 & 36.4 & $\begin{array}{l}\text { Aqueous cau- } \\
\text { sal allergen } \\
\text { extracts }\end{array}$ & $\begin{array}{l}\text { Various } \\
\text { doses }\end{array}$ & No & NR & 4 & 42 & Yes \\
\hline $\begin{array}{l}\text { Hellkvist }{ }^{(24)} \text {, } \\
2018\end{array}$ & 51 & $\begin{array}{l}\text { Birch and } \\
\text { grass } \\
\text { pollen }\end{array}$ & 31.8 & 68.6 & $\begin{array}{l}\text { ALK Alutard } \\
\text { 5-grasses and } \\
\text { ALK Alutard } \\
\text { Birch }\end{array}$ & 1000 & No & $\begin{array}{l}\text { Placebo: saline } \\
\text { and albumin }\end{array}$ & 4 & $24-36$ & NR \\
\hline Wang $^{(9)}, 2019$ & 81 & HDM & 34.5 & 53.1 & $\begin{array}{l}\text { Standardized } \\
\text { house dust } \\
\text { mite allergen } \\
\text { extracts }\end{array}$ & $50 \mathrm{TU}$ & No & NR & 4 & 52 & NR \\
\hline $\begin{array}{l}\text { Konradsen }{ }^{(25)} \\
2020\end{array}$ & 26 & $\begin{array}{l}\text { Birch } \\
\text { and/ } \\
\text { or grass } \\
\text { pollen }\end{array}$ & 22.3 & 61.5 & $\begin{array}{l}\text { Alutard birch } \\
\text { or grass } \\
\text { pollen }\end{array}$ & $1000 \mathrm{SQU}$ & Yes & $\begin{array}{l}\text { Placebo: ALK } \\
\text { diluent }\end{array}$ & 4 & $92-104$ & NR \\
\hline $\begin{array}{l}\text { Skaarup }{ }^{(26)} \\
2020\end{array}$ & 36 & $\begin{array}{l}\text { Grass } \\
\text { pollen }\end{array}$ & 30.7 & 52.8 & $\begin{array}{l}\text { ALK } 225 \text { Solu- } \\
\text { prick Phleum } \\
\text { Pratens }\end{array}$ & $1000 \mathrm{SQU}$ & Yes & $\begin{array}{l}\text { Placebo: isotonic } \\
\text { saline }\end{array}$ & 4 & 144 & NR \\
\hline $\begin{array}{l}\text { Terada }{ }^{(27)}, \\
2020\end{array}$ & 18 & $\begin{array}{l}\text { Japanese } \\
\text { cedar } \\
\text { pollen }\end{array}$ & 43 & 33.3 & $\begin{array}{l}\text { Japanese } \\
\text { cedar pollen } \\
\text { extract }\end{array}$ & $20 \mathrm{JAU}$ & No & Placebo: saline & 4 & 130 & NR \\
\hline $\begin{array}{l}\text { Thompson }{ }^{(28)} \\
2020\end{array}$ & 21 & $\begin{array}{l}\text { Mountain } \\
\text { cedar } \\
\text { pollen }\end{array}$ & 37.6 & 42.9 & $\begin{array}{l}\text { Mountain } \\
\text { cedar pollen, } \\
\text { ALK-Abelló }\end{array}$ & $\begin{array}{l}1: 2000 \\
w / v\end{array}$ & No & $\begin{array}{l}\text { Placebo: glycerin } \\
\text { and saline }\end{array}$ & 4 & $15-19$ & NR \\
\hline $\begin{array}{l}\text { Weinfeld }{ }^{(29)}, \\
2020\end{array}$ & 13 & $\begin{array}{l}\text { Grass } \\
\pm \text { birch } \\
\text { pollen }\end{array}$ & NR & NR & $\begin{array}{l}\text { ALK Alutard } \\
5 \text {-grasses }\end{array}$ & $1000 \mathrm{SQU}$ & Yes & $\begin{array}{l}\text { Placebo: ALK } \\
\text { diluent* }\end{array}$ & 4 & 84 & NR \\
\hline
\end{tabular}

same dosage throughout the study. Preseason booster doses were given in 3 studies ${ }^{(25,26,29)}$. Five studies had follow-up periods longer than 52 weeks $^{(8,25-27,29)}$.

\section{Comparisons}

Ten of the 11 RCTs compared ILIT with placebo ${ }^{(19-22,24-29)}$ and 1 $\mathrm{RCT}$ compared ILIT with the conventional SCIT(8).

\section{Outcomes}

Combined symptom and medication score (CSMS)

Five RCTs compared CSMS in patients with seasonal ARC

between the ILIT and placebo ${ }^{(20,22,26-28)}$. The short-term effect of ILIT on the CSMS improvement favored ILIT (SMD - $0.51,95 \% \mathrm{CI}$ -0.88 to $-0.14, p<0.01,5 R C T s)^{(20,22,26-28)}$. An 12 of $24 \%$ represented low heterogeneity. Data are illustrated in Figure 2. There was no 


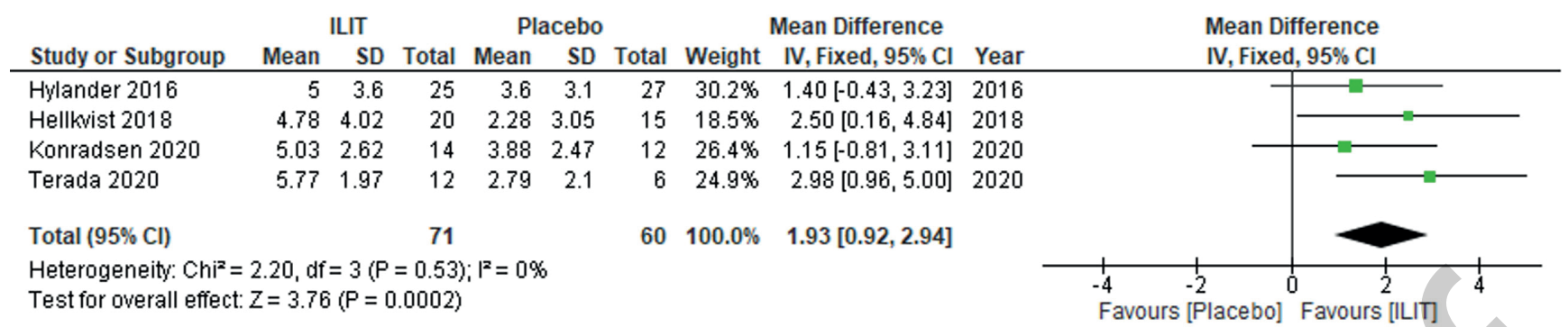

Figure 3. Medium-term improvement in visual analog scale in allergic symptoms: intralymphatic immunotherapy versus placebo. ILIT = intralymphatic immunotherapy; $\mathrm{Cl}=$ confidence interval; $\mathrm{df}=$ degrees of freedom.

study assessing medium-term effect. The long-term effect of ILIT was not different from placebo (MD $-3.62,95 \% \mathrm{Cl}-7.61$ to 0.37 , $\mathrm{p}=0.08,1 \mathrm{RCT})^{(26)}$.

\section{Visual analog scale (VAS) of seasonal allergic symptoms} Four RCTs compared the VAS of seasonal allergic symptoms between the ILIT and placebo ${ }^{(21,24,25,27)}$. The short-term effect on VAS improvement (MD 2.98, 95\% Cl 0.96 to $5.00, \mathrm{p}<0.01,1 \mathrm{RCT}$ ) (27), and the medium-term effect (MD 1.93, 95\% 0.92 to 2.94, $\mathrm{p}<0.01,4$ RCTs) favored ILIT ${ }^{(21,24,25,27)}$. Data are illustrated in Figure 3. An 12 of $0 \%$ represented low heterogeneity. The long-term effect of ILIT was not different from placebo (MD 0.43, 95\% Cl -2 to $2.86, \mathrm{p}=0.73,1 \mathrm{RCT})^{(27)}$.

One RCT compared the VAS scores between ILIT and SCIT in patients with seasonal ARC. Both ILIT and SCIT improved the VAS scores when compared with the baseline. There were no differences between ILIT and SCIT in both the medium-term effect (MD $0.02,95 \% \mathrm{Cl}-0.35$ to $0.39, \mathrm{p}=0.92,1 \mathrm{RCT}$ ) and the long-term effect (MD $0.33,95 \% \mathrm{Cl}-0.04$ to $0.71, \mathrm{p}=0.08,1 \mathrm{RCT})^{(8)}$.

\section{Symptom score (SS)}

Three RCTs assessed SS between the ILIT and placebo ${ }^{(20,25,28)}$. The short-term effect of ILIT on SS was not different from placebo (SMD $-0.28,95 \% \mathrm{Cl}-0.74$ to $0.18, \mathrm{p}=0.23,3 \mathrm{RCTs}$ ). An 12 of $0 \%$ represented low heterogeneity.

\section{Medication score (MS)}

Three RCTs assessed MS between the ILIT and placebo $(20,25,28)$. The short-term effect of ILIT on MS was not different from placebo (SMD $-0.14,95 \% \mathrm{Cl}-0.16$ to $0.29, \mathrm{p}=0.48,3 \mathrm{RCTs}$ ). An 12 of $0 \%$ represented low heterogeneity.

\section{Disease-specific quality of life}

Four RCTs assessed the disease-specific QOL score ${ }^{(19,20,24,25)}$, of which 3 RCTs assessed seasonal ARC ${ }^{(20,24,25)}$ and 1 RCT assessed perennial ARC ${ }^{(19)}$. The Asthma Quality of Life Questionnaire was used in $1 \mathrm{RCT}^{(25)}$. The Rhinoconjunctivitis Quality of Life Questionnaire (RQLQ) was used in $2 \mathrm{RCTs}^{(20,24)}$. The short-term effect of ILIT was not different from placebo (SMD -0.4, 95\%Cl - 1.21 to $0.42, p=0.34,2 R C T s)^{(20,24)}$. The validated mini RQLQ was used in $1 \mathrm{RCT}$ which assessed perennial ARC. There was no statistical difference between ILIT and placebo but the data could not be extracted $^{(19)}$.

\section{Subgroup analysis by pediatric subgroup}

There was no study assessing pediatric patients.

\section{Subgroup analysis by ARC subtype}

One RCT studied patients with perennial ARC ${ }^{(19)}$. The mini RQLQ were assessed and showed no statistical difference between ILIT and placebo (data not shown). The CSMS, SS, MS, and VAS were not assessed in this study.

\section{Subgroup analysis by injection interval}

Subgroup analysis by injection interval was performed. The short-term effect on CSMS improvement favored the 4-week interval of ILIT over placebo (SMD $-0.70,95 \% \mathrm{Cl}-1.15$ to -0.25 , $\mathrm{p}<0.01,4 \mathrm{RCTs})^{(22,26-28)}$. An 12 of $1 \%$ represented low heterogeneity. Benefit of the 2-week interval of ILIT was not shown (SMD $-0.09,95 \% \mathrm{Cl}-0.76$ to $0.59, \mathrm{p}=0.8,1 \mathrm{RCT})^{(20)}$.

\section{Specific lgG4 level}

Eight RCTs assessed specific IgG4 level between the ILIT and placebo ${ }^{(19-21,24-27,29)}$. One RCT assessed specific IgG4 level only for preseason booster dose ${ }^{(29)}$. Data from 2 RCTs were not extracted due to selecting outcome bias ${ }^{(24,27)}$. The short-term effect of ILIT increased specific IgG4 level (SMD $0.7,95 \% \mathrm{Cl} 0.16$ to 1.24 , $\mathrm{p}=0.01,4 \mathrm{RCTs})^{(19-21,26)}$. An 12 of $48 \%$ represented moderate heterogeneity. There were no differences in the medium-term effect (SMD 0.37, 95\%Cl -0.03 to $0.78, \mathrm{p}=0.07,4 \mathrm{RCTs}, \mathrm{I2}=9 \%)^{(21,25,26,30)}$ and the long-term effect (MD $-0.02,95 \% \mathrm{Cl}-0.72$ to $0.68, \mathrm{p}=0.95$, $1 \mathrm{RCT})^{(26)}$. Data are illustrated in Figure 4.

\section{Specific IgE level}

Eight RCTs assessed specific lgE level between ILIT and placebo ${ }^{(19-21,24-28)}$. Data were not provided in one RCT ${ }^{(27)}$. The ILIT effects did not decrease the specific IgE level at any time point: short-term (SMD $0.01,95 \% \mathrm{Cl}-0.27$ to $0.3, \mathrm{p}=0.92,6 \mathrm{RCTs})^{(19-}$ 


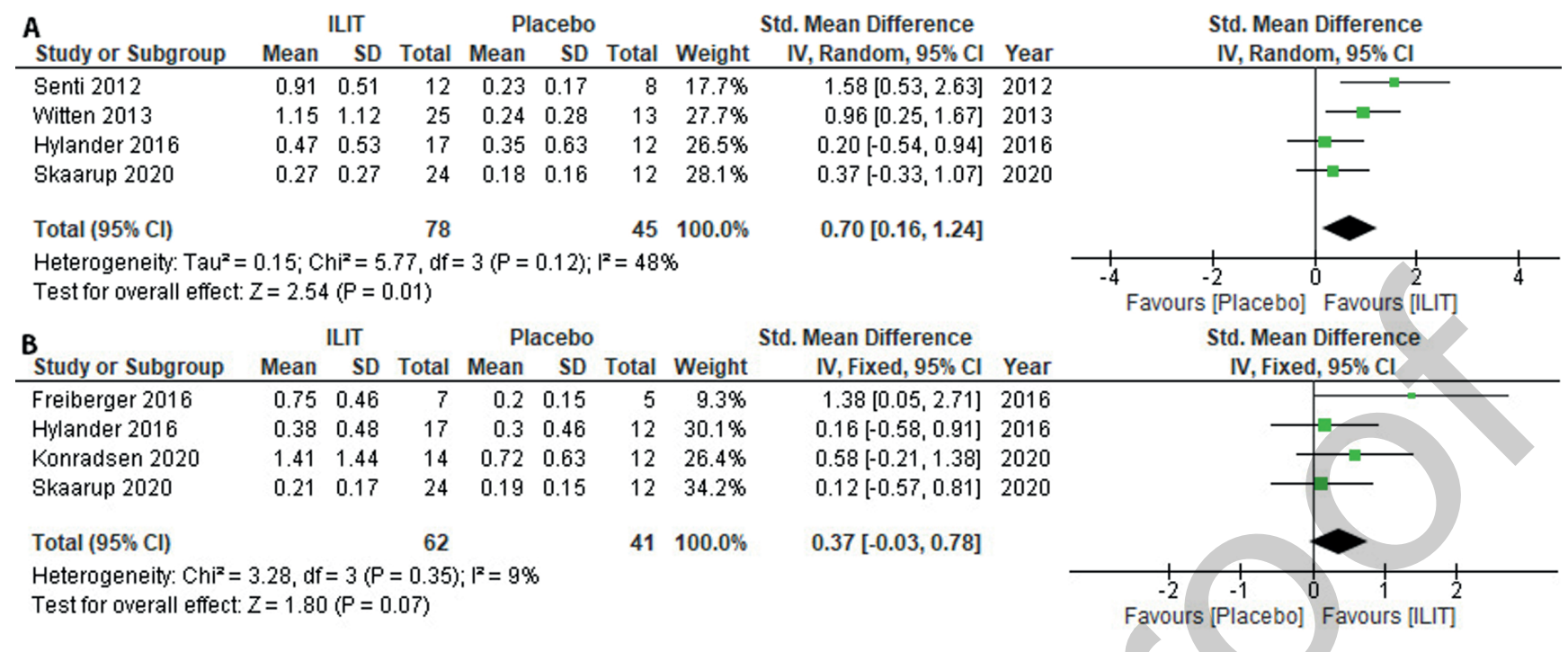

Figure 4. Change on specific IgG4 level: intralymphatic immunotherapy versus placebo. (A) Short-term. (B) Medium-term. ILIT= intralymphatic immunotherapy; $\mathrm{Cl}$ = confidence interval; $\mathrm{df}=$ degrees of freedom; Std. mean difference = standardized mean difference.

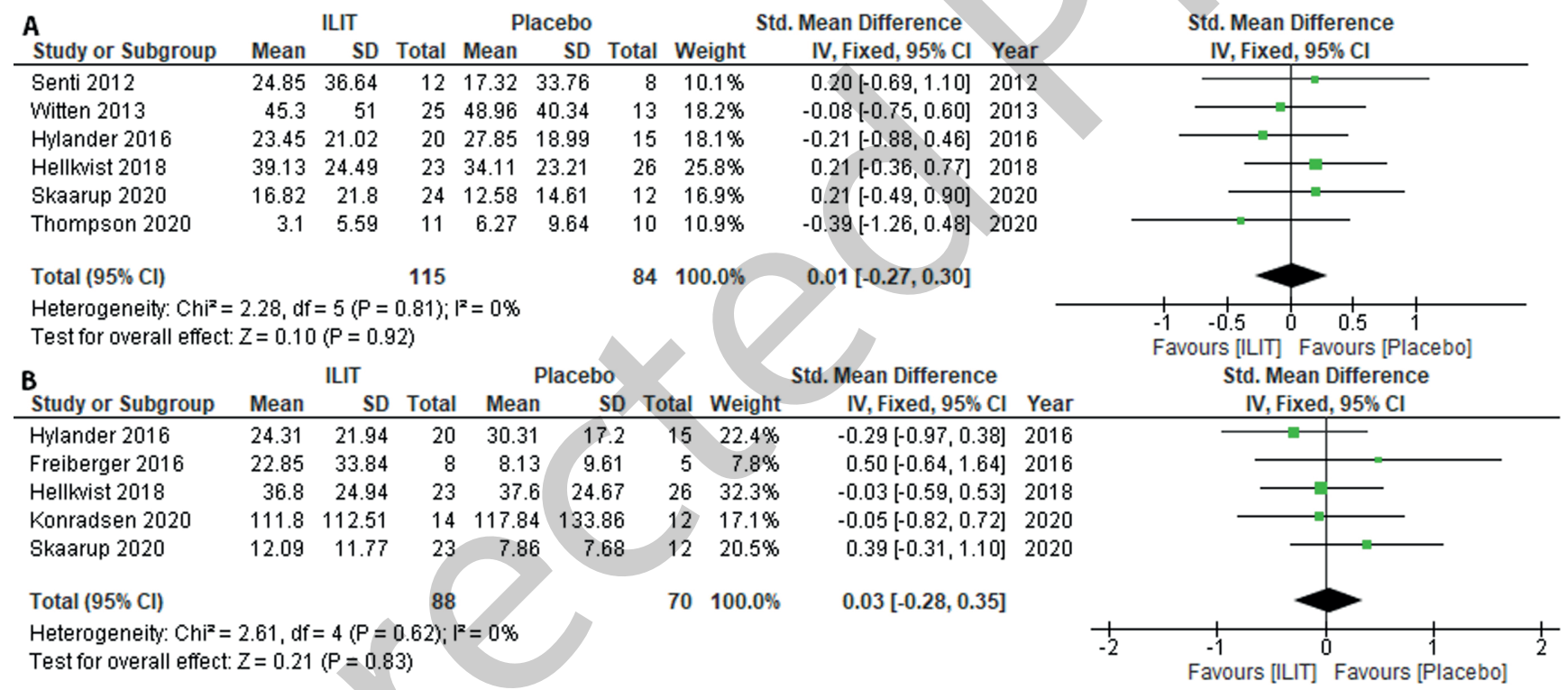

Figure 5. Change on specific IgE level: intralymphatic immunotherapy versus placebo. (A) Short-term. (B) Medium-term. ILIT = intralymphatic immunotherapy; $\mathrm{Cl}=$ confidence interval; $\mathrm{df}=$ degrees of freedom; $\mathrm{Std}$. mean difference = standardized mean difference.

21,24,26,28), medium-term (SMD 0.03, $95 \% \mathrm{Cl}-0.28$ to $0.35, \mathrm{p}=0.83,5$ $\mathrm{RCTs})^{(20,21,25,26,30)}$, and long-term (SMD $0.18,95 \% \mathrm{Cl}-0.52$ to 0.88 , $\mathrm{p}=0.62,1 \mathrm{RCT})^{(26)}$. An $\mathrm{I} 2$ of $0 \%$ represented low heterogeneity in all meta-analyses. Data are illustrated in Figure 5. One RCT compared between the ILIT and SCIT, the effects of SCIT significantly decreased specific lgE level in all 3 periods: short-term (MD 6.40, $95 \% \mathrm{Cl} 1.85$ to $10.95, \mathrm{p}<0.01,1 \mathrm{RCT}$ ), medium-term (MD 5.58, $95 \% \mathrm{Cl} 1.03$ to $10.13, \mathrm{p}=0.02,1 \mathrm{RCT}$ ), and long-term (MD 7.54, $95 \% \mathrm{Cl} 3.18$ to $11.09, \mathrm{p}<0.01,1 \mathrm{RCT})^{(8)}$.

\section{Adverse events}

All the 11 included RCTs assessed the safety of ILIT and reported adverse events. ILIT had more local reactions than placebo but there were no differences in systemic adverse events. Data are illustrated in Table 2. ILIT had fewer adverse events than SCIT (RR $0.28,95 \% \mathrm{Cl} 0.12$ to $0.64, \mathrm{p}<0.01,1 \mathrm{RCT})^{(8)}$. Anaphylaxis and death were assessed in a total of 989 ILIT injections ( 2 cohorts and $11 \mathrm{RCTs})$, there was no death but two (0.2\%) anaphylaxis events were reported ${ }^{(23)}$.

\section{Quality of the included studies}

Most of the 11 RCTs had risks of selection bias and attrition bias (Figure 6). There were low risks of bias in allocation concealment ( $55 \%$ of the RCTs), incomplete outcome data (55\%), random sequence generation (70\%), blinding of outcome assessment 
Table 2. Risk ratios of adverse events: Intralymphatic immunotherapy vs placebo.

\begin{tabular}{|c|c|c|c|c|c|c|c|}
\hline \multirow[t]{2}{*}{ Adverse events } & \multirow{2}{*}{$\begin{array}{l}\text { Number } \\
\text { of studies }\end{array}$} & \multicolumn{2}{|c|}{ ILIT } & \multicolumn{2}{|c|}{ Placebo } & \multirow{2}{*}{$\begin{array}{l}\text { Risk ratio } \\
(95 \% \mathrm{CI})\end{array}$} & \multirow[t]{2}{*}{$p$ value } \\
\hline & & $\begin{array}{l}\text { Number of } \\
\text { injections }\end{array}$ & $\begin{array}{l}\text { Number of } \\
\text { events }\end{array}$ & $\begin{array}{l}\text { Number of } \\
\text { injections }\end{array}$ & $\begin{array}{l}\text { Number of } \\
\text { events }\end{array}$ & & \\
\hline \multicolumn{8}{|c|}{ Local reactions } \\
\hline $\begin{array}{l}\text { Local lymph node swelling } \\
(19-21,24,26)\end{array}$ & 6 & 368 & 102 & 265 & 5 & $\begin{array}{c}7.53 \\
(1.82,31.15)\end{array}$ & 0.01 \\
\hline Local redness ${ }^{(21,24,28,29)}$ & 4 & 194 & 43 & 169 & 0 & $\begin{array}{c}16.75 \\
(4.1,68.41)\end{array}$ & $<0.01$ \\
\hline Local itching ${ }^{(21,24,29)}$ & 3 & 161 & 23 & 139 & 10 & $\begin{array}{c}5.48 \\
(1.80,16.68)\end{array}$ & $<0.0$ \\
\hline \multicolumn{8}{|c|}{ Systemic reactions } \\
\hline $\operatorname{Skin}^{(19,21,24,26,29)}$ & 5 & 281 & 10 & 223 & 1 & $\begin{array}{c}2.93 \\
(0.85,10.02)\end{array}$ & 0.09 \\
\hline Eye/nasal symptoms ${ }^{(19-21,24,26,27,29)}$ & 7 & 404 & 47 & 283 & 25 & $1.17(0.73,1.87)$ & 0.52 \\
\hline Headache/fatigue ${ }^{(19,20,24,26,29)}$ & 5 & 307 & 22 & 220 & 12 & $1.25(0.62,2.53)$ & 0.53 \\
\hline Pulmonary symptoms ${ }^{(19,20,29)}$ & 3 & 136 & 6 & 72 & 4 & $0.74(0.23,2.42)$ & 0.62 \\
\hline Abdoment/nausea ${ }^{(19-21,24,29)}$ & 5 & 284 & 11 & 205 & 8 & $0.81(0.37,1.78)$ & 0.60 \\
\hline Anaphylaxis ${ }^{(19-22,24-29)}$ & 10 & 536 & 0 & 408 & 0 & NA & NA \\
\hline
\end{tabular}

(80\%), and selective reporting (80\%). When the quality of 2 cohorts was assessed, both of them had high risks of bias. The total MINORS scores of these studies were $9^{(23)}$ and $10^{(9)}$ out of 16 .

\section{Discussion}

This systematic review demonstrated the short-term benefits of ILIT in treating seasonal ARC patients compared with placebo. The short-term effects of ILIT significantly improved the CSMS and VAS.

AIT is a step-up treatment for patients with ARC who were not improved by pharmacotherapies ${ }^{(31)}$. Nevertheless, SLIT needs high compliance and SCIT requires more than 70 injections over 3-5 years ${ }^{(32)}$. As a result, most patients with ARC feel unsatisfied with the inconveniences of these conventional AITs ${ }^{(33)}$. ILIT, a new form of AIT that requires 3 intralymphatic injections over 2 months, could be a potential alternative for these patients. The benefits of ILIT for treating patients with ARC have been postulated and investigated in recent years ${ }^{(3)}$. Direct intralymphatic injection enhances the availability of allergen in secondary lymphoid organs $s^{(5)}$. An animal experiment demonstrated that the antigens that reached the lymph nodes after intralymphatic administration were 100-fold higher than those after subcutaneous injection at the same dose ${ }^{(34)}$. A human study revealed that the allergen fragments reached the deep subcutaneous lymph nodes 20 minutes after the intralymphatic injection into a superficial inguinal lymph node ${ }^{(10)}$. On the contrary, only a small fraction of antigen reached the lymph nodes after 24 hours of subcutaneous administration with the same dose at $10 \mathrm{~cm}$ above the contralateral superficial lymph node ${ }^{(10)}$. ILIT requires a lower total dose than the conventional AIT. The 3-year cumulative dose of SCIT is 1,000-fold higher than ILIT ${ }^{(8)}$. In addition, the treatment duration of ILIT is shorter. For these reasons, ILIT should be considered as another option of $\mathrm{AIT}^{(11)}$.

The short-term and medium-term beneficial effects were shown for ILIT on VAS improvement. The reduction of CSMS reflected an improvement in symptom severity and/or a decrease in the usage of rescue medications ${ }^{(15)}$. The short-term benefit of ILIT on CSMS reduction was demonstrated in this review. However, the standardized mean difference of around 0.5 may not be clinically significant. The medium-term benefit of ILIT on improving CSMS remained unavailable and the long-term benefit was not shown. Disease specific quality of life, symptom score, and medication score were not different between the ILIT and control groups. Discordance between VAS, CSMS and disease specific quality of life, symptom score raises a concern that the effects of ILIT should not be overstated. Unlike the effect of other AITs on specific IgE level ${ }^{(7)}$, ILIT did not decrease the specific lgE level at any time point. Although the IgG4 level was increased after ILIT, this effect deteriorated after 24 weeks. This finding was similar to the effect on $\mathrm{CSMS}^{(26)}$. The short-term benefit on CSMS was demonstrated in the 4-week injection interval but not the 2-week interval in this study. This finding suggested that the 2-week interval was not enough time for adequate immune responses. The allergen-specific immune responses, including memory B-cell formation and affinity maturation need sufficient time to develop after allergens are present in lymph follicles ${ }^{(35)}$. 


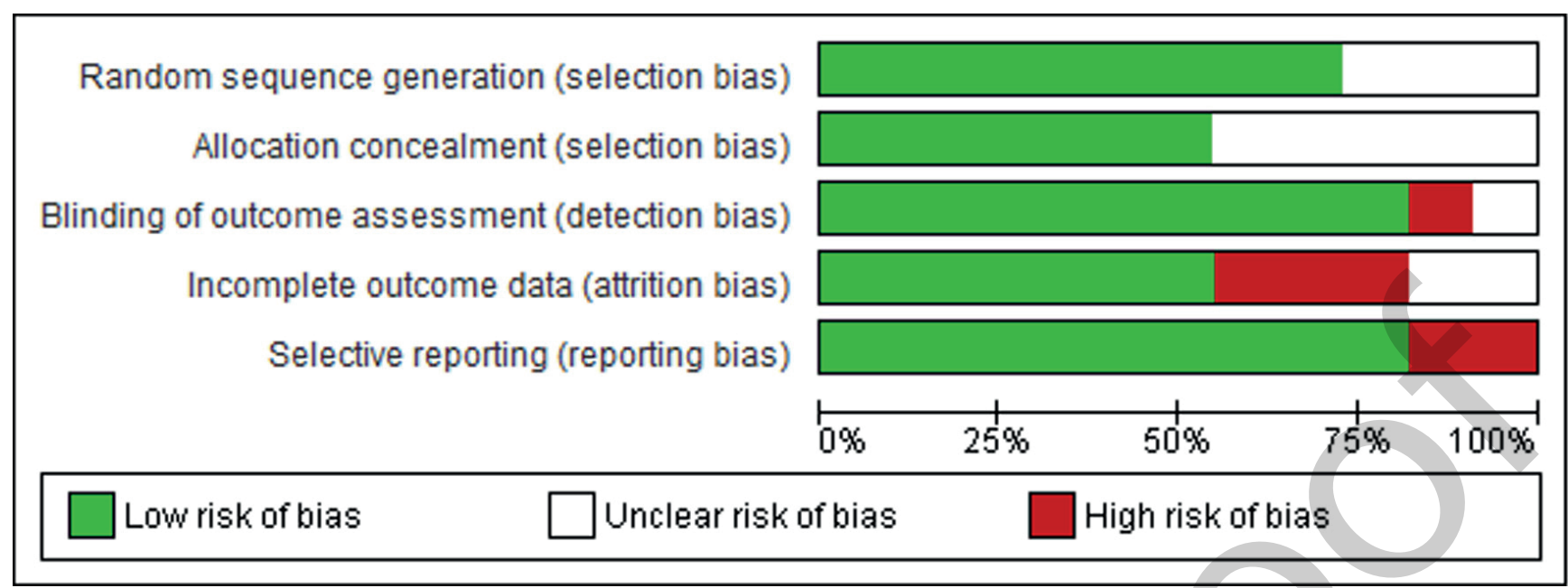

Figure 6. Each risk of bias item for each included study.

AIT is expected to provide long-term favorable therapeutic outcomes. However, this review did not demonstrate the longterm benefits of ILIT. There were only a few of the included RCTS that studied the long-term effects of ILIT. Two RCTs reported no long-term benefits of ILIT (after 52 weeks). The dosage of ILIT in these studies might be suboptimal ${ }^{(26,27)}$. This review could not demonstrate the optimal dose for long-term benefits of ILIT. Moreover, the ILIT protocols in most of the included studies were 3 injections of the same dose within 2 months. Escalating dose and/or booster dose might provide better therapeutic effects as well as long-term effects. The protocols with escalating dose and/or booster dose have not, however, been extensively investigated. Mixed results were reported by the studies that investigated a booster dose. Konradsen et al.(25) assessed the effects of one additional booster dose after one year. They demonstrated the clinical improvements in symptom score and medication score but the increased specific lgG4 level was maintained at the same level as the first pollen season (before the booster dose). In concordance with this finding, Weinfeld et al. ${ }^{(29)}$ demonstrated that the preseason booster of ILIT decreased the eyes symptom score and increased the specific IgG4 level. In contrast, Skaarup et al. ${ }^{(26)}$ reported that the preseason booster did not provide additional effects. Therefore, the benefits of booster injection were inconclusive.

ILIT had fewer adverse events than SCIT in both local and systemic reactions. Lee et al. ${ }^{(23)}$ reported two anaphylaxis events in a cohort study. An aqueous non-standardized allergen extract was used in this cohort. Other studies that used standardized allergen extracts did not report any anaphylaxis or other severe systemic adverse events. ILIT also had risks of local reaction. Allergen extracts used in 9 out of the 11 RCTs were aluminumbased adjuvant. It is possible that aluminum increases the risk of local reaction. In addition, glycerin in glycerinated extract used by Thompson et al. ${ }^{(28)}$ might be the cause of local redness.
The limitations of this systematic review were that the majority of studies assessed patients with seasonal ARC with only a few studies assessed perennial ARC. There were no pediatric patients included in the study. Multi-center trials with large sample sizes and long-term follow-up greater than 1 year are required to determine the standardized dose for ILIT and its long-term efficacy.

\section{Conclusion}

Evidence from 11 randomized controlled trials showed shortterm benefits of ILIT for treating adult patients with seasonal ARC. These short-term benefits included improvements of the combined symptom and medication score and the visual analogue scale of ARC symptoms. The long-term effects were inconclusive due to a lack of studies. Benefits of ILIT for treating perennial ARC were inconclusive. There was no data for pediatric patients. ILIT was safe and well-tolerated.

\section{Authorship contribution}

MPH: study design, search, study selection, data collection, data analysis, drafting the article, and final approval; KSe: search, study selection, data collection, revising the article, and final approval; WC: search, study selection, revising the article, and final approval; KSn: conception, study design, data analysis, drafting the article, and final approval.

\section{Conflict of interest}

Kornkiat Snidvongs received Honoraria for speaking at symposia from Merck Sharp \& Dohme, Mylan, and Menarini.

Minh P. Hoang, Kachorn Seresirikachorn, Wirach Chitsuthipakorn declare that they have no conflict of interest.

\section{Financial disclosure}

This is an unfunded project. 


\section{References}

1. Bousquet J, Schunemann HJ, Togias A, et al. Next-generation Allergic Rhinitis and Its Impact on Asthma (ARIA) guidelines for allergic rhinitis based on Grading of Recommendations Assessment, Development and Evaluation (GRADE) and real-world evidence. J Allergy Clin Immunol. 2020; 145(1): 70-80 e73.

2. Wise SK, Lin SY, Toskala E, et al. International Consensus Statement on Allergy and Rhinology: Allergic Rhinitis. Int Forum Allergy Rhinol. 2018; 8(2): 108-352.

3. Passalacqua G, Canonica GW. Allergen Immunotherapy: History and Future Developments. Immunol Allergy Clin North Am. 2016; 36(1): 1-12.

4. Globinska A, Boonpiyathad T, Satitsuksanoa $P$, et al. Mechanisms of allergen-specific immunotherapy: Diverse mechanisms of immune tolerance to allergens. Ann Allergy Asthma Immunol. 2018; 121(3): 306-312.

5. von Moos S, Kundig TM, Senti G. Novel administration routes for allergen-specific immunotherapy: a review of intralymphatic and epicutaneous allergen-specific immunotherapy. Immunol Allergy Clin North Am. 2011; 31(2): 391-406, xi.

6. Zinkernagel RM, Ehl S, Aichele P, Oehen S, Kundig T, Hengartner $\mathrm{H}$. Antigen localisation regulates immune responses in a doseand time-dependent fashion: a geographical view of immune reactivity. Immunol Rev. 1997; 156: 199-209.

7. Akdis CA, Akdis M. Mechanisms of allergenspecific immunotherapy and immune tolerance to allergens. World Allergy Organ J. 2015; 8(1): 17

8. Senti G, Prinz Vavricka BM, Erdmann I, et al. Intralymphatic allergen administration renders specific immunotherapy faster and safer: a randomized controlled trial. Proc Natl Acad Sci U S A. 2008; 105(46): $17908-$ 17912.

9. Wang K, Zheng R, Chen Y, et al. Clinical efficacy and safety of cervical intralymphatic immunotherapy for house dust mite allergic rhinitis: A pilot study. Am J Otolaryngol. 2019; 40(6): 102280

10. Senti G, Johansen $P$, Kundig TM Intralymphatic immunotherapy. Curr Opin Allergy Clin Immunol. 2009; 9(6): 537-543.

11. Senti G, Freiburghaus AU, LarenasLinnemann D, et al. Intralymphatic Immunotherapy: Update and Unmet Needs. Int Arch Allergy Immunol. 2019; 178(2): 141-149.

12. Dhami S, Nurmatov U, Arasi S, et al. Allergen immunotherapy for allergic rhinoconjunctivitis: A systematic review and meta-analysis. Allergy Eur J Allergy Clin Immunol. 2017; 72(11): 1597-1631.

13. Moher D, Liberati A, Tetzlaff J, Altman DG, Group P. Preferred reporting items for systematic reviews and meta-analyses: the PRISMA statement. PLoS Med. 2009; 6(7): e1000097.

14. Bousquet J, Khaltaev N, Cruz AA, et al.
Allergic Rhinitis and its Impact on Asthma (ARIA) 2008 update (in collaboration with the World Health Organization, GA(2)LEN and AllerGen). Allergy. 2008; 63 Suppl 86: 8-160.

15. Pfaar O, Demoly P, Gerth van Wijk R, et al. Recommendations for the standardization of clinical outcomes used in allergen immunotherapy trials for allergic rhinoconjunctivitis: an EAACI Position Paper. Allergy. 2014; 69(7): 854-867.

16. Higgins JP, Altman DG, Gotzsche PC, et al. The Cochrane Collaboration's tool for assessing risk of bias in randomised trials. BMJ. 2011; 343: d5928.

17. Slim K, Nini E, Forestier D, Kwiatkowski F, Panis Y, Chipponi J. Methodological index for non-randomized studies (minors): development and validation of a new instrument. ANZ J Surg. 2003; 73(9): 712-716.

18. Review Manager (RevMan) 5.4 ed Copenhagen: The Nordic Cochrane Centre. The Cochrane Collaboration; 2020.

19. Senti G, Crameri R, Kuster D, et al Intralymphatic immunotherapy for cat allergy induces tolerance after only 3 injections. J Allergy Clin Immunol. 2012; 129(5): 1290-1296.

20. Witten M, Malling HJ, Blom L, Poulsen BC, Poulsen LK. Is intralymphatic immunotherapy ready for clinical use in patients with grass pollen allergy? J Allergy Clin Immunol. 2013; 132(5): 1248-1252.e1245.

21. Hylander T, Larsson O, Petersson-Westin $U$, et al. Intralymphatic immunotherapy of pollen-induced rhinoconjunctivitis: a double-blind placebo-controlled trial. Respir Res. 2016; 17: 10.

22. Patterson AM, Bonny AE, Shiels WE, 2nd, Erwin EA. Three-injection intralymphatic immunotherapy in adolescents and young adults with grass pollen rhinoconjunctivitis. Ann Allergy Asthma Immunol. 2016; 116(2): 168-170.

23. Lee SP, Choi SJ, Joe E, et al. A Pilot Study of Intralymphatic Immunotherapy for House Dust Mite, Cat, and Dog Allergies. Allergy Asthma Immunol Res. 2017; 9(3): 272-277.

24. Hellkvist L, Hjalmarsson E, Kumlien Georén $S$, et al. Intralymphatic immunotherapy with 2 concomitant allergens, birch and grass: A randomized, double-blind, placebo-controlled trial. J Allergy Clin Immunol. 2018; 142(4): 1338-1341.e1339.

25. Konradsen JR, Grundström J, Hellkvist L, et al. Intralymphatic immunotherapy in pollen-allergic young adults with rhinoconjunctivitis and mild asthma: A randomized trial. J Allergy Clin Immunol. 2020; 145(3): 1005-1007.e1007.

26. Skaarup SH, Schmid JM, Skjold T, Graumann O, Hoffmann HJ. Intralymphatic immunotherapy improves grass pollen allergic rhinoconjunctivitis: A 3-year randomized placebo-controlled trial. J Allergy Clin Immunol. 2020. S0091-6749(20)30964-7.

27. Terada T, Omura S, Kikuoka $Y$, et al. Sustained effects of intralymphatic pollen- specific immunotherapy on Japanese cedar pollinosis. Rhinology. 2020; 58(3): 241-247.

28. Thompson CP, Silvers S, Shapiro MA. Intralymphatic immunotherapy for mountain cedar pollinosis: A randomized, doubleblind, placebo-controlled trial. Ann Allergy Asthma Immunol. 2020; 125(3): 311-318 e312.

29. Weinfeld D, Westin U, Hellkvist L, Mellqvist UH, Jacobsson I, Cardell LO. A preseason booster prolongs the increase of allergen specific IgG4 levels, after basic allergen intralymphatic immunotherapy, against grass pollen seasonal allergy. Allergy Asthma Clin Immunol. 2020; 16: 31

30. Freiberger SN, Zehnder M, Gafvelin G, Grönlund H, Kündig TM, Johansen P. IgG4 but no IgG1 antibody production after intralymphatic immunotherapy with recombinant MAT-Feld1 in human. Allergy. 2016; 71 (9): 1366-1370.

31. Seidman MD, Gurgel RK, Lin SY, et al. Clinical practice guideline: allergic rhinitis executive summary. Otolaryngol Head Neck Surg. 2015; 152(2): 197-206.

32. Frew AJ. 25. Immunotherapy of allergic disease. J Allergy Clin Immunol. 2003; 111 (2 Suppl): S712-719.

33. Bender BG, Lockey RF. Solving the Problem of Nonadherence to Immunotherapy. Immunol Allergy Clin North Am. 2016; 36(1): 205-213.

34. Martinez-Gomez JM, Johansen $P$, Erdmann I, Senti G, Crameri R, Kundig TM. Intralymphatic injections as a new administration route for allergen-specific immunotherapy. Int Arch Allergy Immunol. 2009; 150(1): 59-65.

35. Kundig TM, Johansen P, Bachmann MF, Cardell LO, Senti G. Intralymphatic immunotherapy: time interval between injections is essential. J Allergy Clin Immunol. 2014; 133(3): 930-931.

Kornkiat Snidvongs

Department of Otolaryngology

Faculty of Medicine

Chulalongkorn University

1873 Rama 4 Road

Pathumwan

Bangkok 10330

Thailand

Tel: (+66) 2-256-4103

Fax: (+66) 2-252-7787

E-mail: drkornkiat@yahoo.com 